\title{
Performance Contract and Performance Evaluation of State-Owned Enterprises: Insights from the Goal Setting Theory
}

\author{
Samuel Nana Yaw Simpson ${ }^{1}$ \\ Department of Accounting \\ University of Ghana Business School \\ P. O. Box LG 78, Legon, Accra \\ Ghana
}

Received: May 08, 2013 Accepted: May 27, 2013 DOI: 10.5296/jpag.v3i2.3744

\begin{abstract}
Performance contract (PC) is one of the initiatives under the impulse of reforming State-Owned Enterprises (SOEs) to among other things, ensure improved SOE performance. Studies however show mixed results in relation to improved SOE performance, and the general perception is that targets in PCs are not challenging enough. Drawing on the goal setting theory, this article provides further theoretical explanations for the application and impact of PCs using evidence from Ghana, the first Anglophone nation in Africa to adopt and implement the PC reform programmes. Relying primarily on data from PCs, SOE evaluation reports, and interviews, findings suggest that the quality of targets in PCs has been improving over the years. Moreover, the goal setting theory element, commitment, is crucial to achieving desirable outcome from PC as a performance evaluation tool.
\end{abstract}

Keywords: performance contract, state enterprises, goal-setting theory, Ghana.

\footnotetext{
${ }^{1}$ Corresponding email: snysamuel@ug.edu.gh Alternative email: snysamuel@gmail.com

The author is grateful to the Research and Conference Committee, UGBS for the partial financial support
} 


\section{Introduction}

Public sector management and performance management in particular has over the years been the core of reforms in the public sectors of many countries at various levels of development; both developed and developing countries, and under various labels such as New Public Management (NPM), Public sector reform (PSR), Reinventing Government and many more (Hood, 1991, 1995; Omoyefa, 2008; Osborne \& Gaebler, 1992;). Unlike developed countries, the part of public sector that attracted many of the reform programmes in many developing countries was the public enterprises sector or the state-owned enterprises (SOE) sector. For instance, about $98 \%$ of the entire reform programmes were public enterprise-related (Nellis, 1989). According to the literature, the focus on the SOE sector stems from the poor performance of the sector. For several years questions were raised about the performance of SOEs, particularly in developing countries. Indeed, they were found to incur huge losses even under the special privileges and concessions as monopolies and monopsonies (e.g. Nellis, 1989; Nellis \& Kikeri, 1989). Among the problems cited for this situation were poor monitoring, managerial and technical challenges, deficient board of directors, poor reporting systems, political interference, too many objectives (absence of focus) and so on (Schick, 1998; Trivedi, 2005; World Bank, 1983, 1995).

These precipitated a public policy, but for developing countries, the source was the IMF and World Bank (Omoyefa, 2008; Schacter, 2000; Uddin \& Hopper, 2003). Aptly noted, “...poor performance often gets most of the attention in public policy" (Johnsen, 2012, pp. 121). Performance contract is one of the interventions to among other things ensure improved performance of public sector organizations including SOEs by encouraging accountability, managerial autonomy, corporate planning, information flow, monitoring, and formalization of SOE/state relationship (Islam, 1993; Jones, 1991; Larbi, 2001; Nellis, 1989; Nellis \& Kikeri, 1989; Shirley, 1989, 1998; Shirley \& Xu, 1998, 2001; Trivedi, 1990;). Within a space of a decade, 11 African countries (Ghana and 10 Francophone nations) had adopted PC as a World Bank intervention; and the number kept rising. By late 1990s, the number of countries had risen to 32 countries signing 550 PCs globally, plus 100,000 PCs from China (Nellis, 1989; Shirley, 1989, 1998; World Bank, 1995).

Since its inception, there have been many more conceptual studies than empirical studies on the PC (e.g. Islam, 1993; Jones, 1991; Larbi, 2001; Nellis, 1989; Shirley \& Xu, 1998, 2001;Trivedi, 1990, 2005;United Nation Report, 1995;). Moreover, the few empirical studies assessing the impact of PC showed mixed results with many showing that PCs on the average have not improved SOE performance (e.g. productivity). Moreover, it is argued with anecdotal evidence that performance targets in the PCs are "soft". To that end, the most common recommendations are, calls for improved efforts on the PC processes and the need to take cognisance of the quality of the goals formulated and targets set. Islam (1993) emphasizes how crucial well-defined goals in a well-designed PC are to ensuring control and management of SOE-government interface, and the implications on performance evaluation. In addition, Dlamini (2001) adds the need to consider in great detail the role of each player: the minister, SOE heads, regulatory and supervisory bodies, as well as the entire range of indicator types (goals). In fact, PCs can improve performance when the targets in the PCs 
are "sensible" (Shirley \& Xu, 2001). However, there are limited studies on PC and goal attainment (Binderkrantz, et al., 2011).

In response to the above and calls for effective performance management tools for the public sector (e.g. Latham et al., 2008), this article primarily examines the use and application of PCs in performance management and evaluation of SOEs. Unlike many of the earlier studies, the current article draws on the goal setting theory: a broader and open theory which encompasses individual and/or team performance (Latham \& Locke, 2007; Locke \& Latham, 1990, 2002, 2006). In fact, many of the existing studies have relied on the agency theory in examining PCs and that perhaps explains the scanty studies on the PC processes including the setting of clear, realistic and credible targets and goals. Consistent with the goal setting theory, this article argues that performance is better when quality goals, objectives, and targets are set, because that makes monitoring, measurement, and evaluation easier and better (Rangan, 2004; Verbeeten, 2008). Moreover, the adoption of this theory in performance management has far more been used in the private sector than the public sector, hence calls for more empirical research to be conducted (Latham et al., 2008).

In the specific case of PCs, the goal setting theory is mentioned in some studies but there was no explicit application of the theory (see e.g., Binderkrantz et al. 2011). This motivates the current article to extend the application of the goal setting theory to performance evaluation in the public sector of developing countries. In fact, the article provides more insight into the PC processes and the implications on SOE performance.

Ghana is chosen as a case in achieving the objectives of this article. This stems from Ghana's pioneering political independence, democratic, social and economic progress in Sub-Saharan Africa (SSA). These have earned her the recognition by many scholars as an authentic site and most researchers' favourite for researching into issues associated with Africa (Ayee, 2008). Furthermore, Ghana has a rich history of SOEs and reforms in SSA due to the vast levels of experience with respect to the research issues raised in this article. For instance, Ghana is the first Anglophone nation in Africa to adopt some of the first SOE reform programmes, especially the reform under study (Nellis, 1989; Nellis \& Kikeri, 1989), and has over the years provided an SOE sector with both 'good' and 'bad' experiences. Evidence therefore from the Ghanaian SOE sector will contribute significantly to the body of knowledge, policy and practices in the SOE sector of other developing countries.

The rest of the article is organized as follows: the next section provides an overview of the literature with respect to the nature and applications of performance contract system, and the theory adopted including the application for performance management studies in public sector organisations. The subsequent section presents the research setting and justifies the data collected, methods and approaches for the article. Data collected is then presented and discussed in the penultimate section. Concluding comments and suggestions for future studies are provided in the final section.

\section{Overview of the Literature}

\subsection{Meaning, Rationale and Nature of Performance Contract}

Performance contracts go by various names in many countries but their attributes and aims 
are similar. PC is a negotiated agreement between government as the owner of public enterprises and the management of enterprises, outlining the underlying principles, rights, obligations and responsibilities of both parties (Nellis, 1989). Later scholars add that the agreement must be formalised; and so must be written and explicit with respect to defining objectives, specifying targets, intentions, obligations, responsibilities, and pledges made by parties concerned, as well as the managerial autonomy required to achieve the expected goals within a given time frame (Caulfield, 2006; Islam, 1993; Shirley \& Xu, 1998, 2001). The sponsors of this initiative concur and add that the responsibilities and expected results must be mutually agreed (OECD, 1999); and performance measured against targets at the end of an agreed period (World Bank, 1995).

As stated earlier, the rationale and purposes of PCs are several though similar. These include restructuring, ensuring managerial autonomy, accountability, performance monitoring and evaluation (see e.g. Christensen, 1998; Dlamini, 2001; Islam, 1993; Larbi, 2001; Mallon, 1994; Trivedi, 2005), and in recent years it has become a performance management strategy in the public sector (Caulfield, 2006). Moreover, there are several models of PC across the globe. Some models with varying pre-contract and post-contract periods; differing in scope, institutionally and procedurally have been identified (Shirley \& Xu, 1998). Senegal's contract plan has three-year contract targets, and the other models have annual targets (Ghana's PC, India's memorandum of understanding, Korea's performance evaluation and monitoring systems, and Philippines' performance monitoring and evaluation system). All these models, except the Pakistanis signalling system, are consistent with the three models identified by Islam (1993) earlier: contract plan (France and Senegal); signalling system (Pakistan); and Memorandum of understanding (India).

Review of the aforementioned models however show that the theoretical underpinnings and fundamental principles are the same and they all seek to ensure improved performance (Islam, 1993; Shirley, 1989; Shirley \& Xu, 1998). Comparing the three most common models, Islam (1993) concludes that performance evaluation forms an integral part of all the three. Moreover the contents are generally standardized, explicating among other things, the vision and mission of SOEs, obligations on the part of SOE managers and government representatives, incentives, and performance evaluation criteria and weights. Furthermore, all the models follow formalised processes, relying on information from SOE's audited annual accounts, budgetary proposals and other reports (e.g. Islam, 1993; Nellis, 1989; Shirley, 1989; Shirley \& Xu, 1998).

Based on experiences across the globe, a typical PC process may consist of any of the following key activities: planning, negotiation, signing, monitoring, and performance evaluation with some variations in relation to the activities. For example in India and Korea, private individuals with professional and diverse expertise (an ad-hoc task force) prepare the technical details of the PCs and sometimes engage in the negotiation, monitoring, and evaluation stages in order to reduce the information and other advantages that SOE mangers may have (Islam, 1993; Shirley \& Xu, 1998). Also in India, corporate planning is a pre-requisite to the PC system since targets are based on the corporate plans. The draft PC should be available to all parties to the contract to peruse before the negotiations (Islam, 1993; 


\section{$\triangle$ Macrothink}

Trivedi, 1990). In the Pakistanis' signalling system (PC), the focus is on selecting general and specific performance measures and evaluation criteria; assigning evaluation criteria weights, and finally negotiating the criterion values (Islam, 1993; Shirley, 1989). Furthermore, the performance targets are set by a special advisory team outside the main stream civil service (Experts Advisory Cell) based on information required and supplied by SOEs before the leaders of the SOEs are invited for negotiations.

Empirically, there have been limited studies on what goes into the target setting processes, how targets and performance criteria weights in the PCs are agreed upon and implemented by SOEs. Many of the existing studies focus on the impact of PC on SOE performance, reducing the information advantage of SOE managers, providing incentives, encouraging commitment from government, accountability and managerial autonomy (e.g. Islam, 1993; Larbi, 2001; Shirley \& Xu, 1998, 2001; Simpson, 2010); but also raise questions on the quality of targets in PCs. They argue that the targets negotiated are easy (soft), leading to SOEs operating under PC achieving less than they could; resulting in what is known as "ratchet effect"(Weitzman, 1980). Specifically, the targets are said to be weak, manipulated and distorted arising from SOE managers' information advantage (see e.g. Larbi, 2001; Shirley \& $\mathrm{Xu}, 1998,2001)$. However, these assertions are seen as anecdotal (Shirley \& Xu, 1998). To be fair to managers of SOEs, the targets consist of other elements (non-economic and qualitative) which cannot be easily manipulated by them.

From the forgoing, PCs are said to be providing a mechanism that ensures desired and planned behaviours from parties to the agreement; thereby ensuring improved performance. Furthermore, there are three fundamental elements common to all the PC models: they are written agreements (enforceable and /or unenforceable); they spell out targets (goals) and expectations (quantitative and / or qualitative); and finally, they specify the parties (e.g. the government, SOE managers) with mutual performance obligation and responsibilities. This means that SOEs will be considered as having performed better when the set targets consistent with the corporate goals and objectives in the PCs are achieved.

\subsection{A Case for Goal-Setting Theory}

From the PC literature, agency theory has been the underlying theory adopted by many authors to explaining the application of PC and the evaluation PC in general ${ }^{2}$. Moreover, many of the studies highlight the importance of improving performance by the standardisation and institutionalisation of goal formulation and performance target setting and evaluation. However, there is minimal theoretical explanation and corroboration of these recommendations, hence the exploration of the goal setting theory.

The goal setting theory postulates that there is a relationship between goals and performance; and that relationship is explained by what the proponents call "Mechanisms or Mediators", and "Moderators" (Latham \& Locke; Locke \& Latham, 1990, 2002, 2006, 2007). Specifically, the theory is concerned with "the effectiveness of specific, difficult goals; the relationship of goals to affect; the mediators of goal effects; the relation of goals to self-efficacy; the moderators of goal effects; and the generality of goal effects across people, tasks, countries,

\footnotetext{
2 See the citations relating to PC in this study.
} 
time spans, experimental designs, goal sources (i.e., self-set, set jointly with others, or assigned), and dependent variables" (Locke \& Latham, 2006, pp. 265). The basis of this is the inductive conclusion that individuals with challenging but specific and explicit goals tend to achieve better results than those with equivocal goals, since the former direct attention, effort and action, and even search for requisite task knowledge, skills and experiences to maximise performance (Locke \& Latham, 1990, 2002, 2006; Latham \& Locke, 2007). They explain that quality goals therefore direct attention and effort; encourage endurance and persistence as well as make the identification of innovative ways of achieving goals crucial. A clear, specific, and "hard" goal does not necessarily result in desirable organisational performance, but the critical issues are: commitment to the targets, complexity of the task, how the targets are framed and developed (as a team or individually), and the availability and use of feedback (Helsin et al., 2008). This means that a goal must not only be specific, but must also be challenging enough to encourage persistence and drive optimum effort, since easy or vague goals generally will not lead to higher levels of effort.

In addition, proponents posit goal moderators and mediators. They explain that these factors may improve or inhibit the effectiveness of even quality goals and targets. They include the ability, knowledge and skills of participants in the performance processes, complexity of task, quality of feedback provided, and commitment. Among these factors, commitment has been described as the sine qua non to ensuring the goal attainment (Latham, et al., 2008). In other words, commitment from all who matter: an "all hands on deck" approach is an essential condition for optimising any goal including achieving the best from PCs.

Commitment according to the literature on goal setting theory can be achieved through persuasive and inspiring communications from leaders; allowing subordinates to participate in goal formulation; equipping those who implement the goals via training, and the provision of incentives (see also Bandura, 1997; Bass, 1985; White \& Locke, 2000).

Empirically, the goal setting theory has been employed in several studies at individual, group and organizational levels to explain and predict the association between goal formulation, implementation and performance (Baum, et al, 2001; Baum \& Locke, 2004; Locke \& Latham, 2006). Within the public sector setting however, relatively few studies have employed this theory (Latham, et al., 2008). Similarly in the broad area of performance management in public sector organisations, the number of studies are growing steadily with evidence from developed countries (Cavalluzzo \& Ittner, 2004; Chun \& Rainey, 2005a, b; Hyndman \& Eden, 2001; Ittner \& Larcker, 2001; Rangan, 2004; Verbeeten 2008).

Emphasizing the importance of goals from evidence gathered from the Netherlands, clearly specifying the goals is essential to preventing the dispersion of organizational energy, reducing and eliminating ambiguity and confusion about objectives, and thus ensures coherence and focus in pursuit of goals (Kaplan, 2001; Rangan, 2004; Verbeeten, 2008). These scholars established that the definition of clear and measurable goals has positive relationship with both quantitative and qualitative performance indicators. CEOs of governmental agencies stated that a focus on mission, objectives, targets and performance measures improves the performance of their agencies (Hyndman \& Eden, 2001). Also in the US, responses from interviews showed that the performance of governmental entities did not 
improve in situations where ambiguity of objectives was high (Cavalluzzo \& Ittner, 2004).

Apart from the quality of goals, other key elements necessary for successful performance management and evaluation system: commitment from leadership; an environment and culture that reward improved performance; active participation by main stakeholders in the process; regular monitoring, feedback and reporting on performance; and linking the performance management to existing structures and organisational strategies(Fryer et al., 2009)

The foregoing studies however were in the context of developed environments, and no evidence has as yet been gathered from developing countries. Moreover, there seems to be no study on performance contracts, a well-known tool for goals and target setting, performance monitoring and evaluation of SOEs.

\section{Research Settings and Methods}

\subsection{Background to the Ghanaian State-Owned Enterprises}

Ghana's SOE sector has a history that dates back to the colonial periods, but the first decade of post-independence (after 1957) experienced unprecedented increase in the number of SOEs. The number of SOEs increased from 4 in 1957 to about 53, few years after independence (Appiah-Kubi, 2001; Killick, 1978; SEC, 1992). Furthermore, the sector contributed conspicuously to employment and GDP: provided $86 \%$ of total registered employment in the country, and contributed about 26\% of Ghana's GDP (Appiah-Kubi, 2001; Killick, 1978).

Successive governments in the late 1960s continued the process of expanding the SOE sector including the establishment of Ghana Industrial Holding Company (GIHOC) to regulate and supervise all SOEs, especially those in the manufacturing sector. By late 1970s to early 1980s, many observers had started questioning the performance of SOEs on account of the large number of public enterprises. Out of 324 SOEs, 181 were wholly owned by the State and 54 were with over 50\% government interest (Opoku, 1997, see also Divestiture Implementation Committee (DIC), 1999). Indeed, the financial returns of the SOEs were low. To correct these, subsequent governments undertook interventionist policies, including the establishment of the State Enterprises Commission (SEC) to among other things, supervise and review the objectives and activities of SOEs through monitoring and recommendation of best management practices to ensure efficient and profitable SOEs.

As far as the SOE sector was concerned, various SOE reform programmes were undertaken covering policy reforms to ensure SOEs operate in a commercial manner, including the control of prices, increased competition, new policies and procedures on government financial support for SOEs, and strict limits on the creation of new SOEs; Institutional and legal reforms to ensure SOE managers have autonomy in day-to-day operations while also strengthening their accountability to Government through restructuring of SEC; Rationalization of the SOE sector through divestitures (sale or liquidation) and mergers to reduce the financial and managerial burden upon Government; Improvement of SOE management and efficiency through staffing reductions, training programs for managers and accountants, installation of MIS, and preparation of corporate plans and financial audits ; 
and Restoration of financial solvency and discipline by clearing cross-debts and arrears and by establishing clear guidelines and procedures for Government- SOE financial relations.

Notable among the reform programmes is the system known as Performance Monitoring and Evaluation (PME) System introduced in the late 1980s to among other things, improve SOE efficiency and productivity; monitor and evaluate their performance; ensure accountability, transparency; and ultimately make them financially self-sustainable. Moreover, the intervention instigated the rebirth of State Enterprises Commission (SEC) charged with the responsibility of promoting efficient and profitable operation of SOEs within the framework of Government policy; reviewing the mission, objectives, programmes and plans of SOEs as well as monitoring and evaluating their performance; undertaking relevant operational and managerial audit and many more to ensure improved SOEs performance (details in PNDCL 170).

\subsection{Research Methods}

To achieve the objectives of this article, the study adopted a qualitative research approach using data gathered from multiple sources. These include documentary evidence: sample PCs and SOE performance evaluation reports; and other empirical data gathered via interview of participants in the Ghanaian PC processes. The sample PCs were used to illicit the content of PCs and the performance reports were used to assess the quality of goals in terms of it being "soft" or "hard". Furthermore, clarifications were sought for evidence from the analysis of these documents during the face to interviews.

The interviewees were officials from the supervisory and regulatory body of SOEs in Ghana as well as the administrators and referee during the signing of the PCs (State Enterprises Commission, SEC); the financiers in the contract representing government (Ministry of Finance and Economic Planning, MOFEP); the sector (parent) ministries of the SOEs; and SOEs themselves.

On the average, each interview lasted for an average of 60 minutes, and the interview questions took both open-ended and semi-structured formats. The open-ended format was used at the initial stages to encourage interviewees to speak broadly and deeply about the issues relating to the study (Glesne \& Peshkin, 1992). This was followed by the semi-structured format to clarify vague points and confirm conclusions that emerged from the discussions. The questions centered on the background to PC in Ghana and the selected cases, the PC processes and key elements, experiences with the implementation of PC, and areas of improvement.

On the whole, eighteen (18) senior officials were interviewed, and they include: three (3) officials from SEC; three (3) schedule officers from the sector Ministries under which the selected cases operate; and three (3) senior officials from each of the purposively selected SOEs. The selection of SOEs was based on years of experience with PCs, performance based on SEC's assessment, and most importantly, willingness to participate in the study. So in all four (4) SOEs were selected from four assessment categories; excellent, above average, average and fair. 


\section{Findings and Discussions}

\subsection{Purpose and Trends in the Use of PC}

SEC through the PME system engages in three (3) inter-related and cyclical activities, viz: corporate planning, performance contract preparation and performance monitoring and evaluation. At the core of these activities is the performance contract system.

An official from SEC explained that, the performance contract system in particular is considered very useful for structuring the relationships between Government and SOEs, as participating SOEs may benefit from a more clearly defined plan of operations and the statement of performance objectives serving as the means of holding SOE management and Boards accountable. Further analysis of sampled PCs and others documentary evidence gathered shows that PCs have multiple aims including restructuring and coordinating the relationship between SOEs and government; Improving SOE performance and quality of service delivery; Fixing accountability issues through the establishment of reporting requirements; Encouraging a culture of planning and systematic way of setting objectives; Increasing the flow of funds from SOEs to government via the payment of dividend and corporate taxes as well as other compulsory deductions (pension); and Improving SOE performance in relation to sales revenue, profitability, and efficiency.

Historically, the system was first applied to core only and strategic SOEs (12). It was later extended to other SOEs and that increased the number to 15 in 1990. The number increased consistently to 47 in 1993 and began to reduce due to concurrent implementation of divestiture programmes (see table 1).

Table 1: Distribution of Participating SOEs in the PC system

\begin{tabular}{llllllllll}
\hline Year & 1999 & 2000 & 2001 & 2005 & 2006 & 2007 & 2008 & 2009 & 2010 \\
\hline No. of SOEs & 19 & 26 & 29 & 27 & 29 & 30 & 29 & 28 & 34 \\
\hline
\end{tabular}

\subsection{Nature of Performance Contract and Processes}

In Ghana, a PC spans a year and defines among other things the intentions, obligations and responsibilities of all parties to the contract. The parties are the SOE in question, the sector or parent ministry and the Ministry of Finance (both representing the government), with SEC acting as the referee and facilitator. By this arrangement, Ministry of Finance (MOF) comes in as the owner, and the sector ministry is to ensure that the vision and mission of the SOEs are consistent with the policies of that ministry.

In terms of content, each contract covers the following standardized themes (sampled PCs and interviews):

- Basic information, including recent performance of the SOE (at least the last 3 years); 
- The mission statement of the SOE;

- The objectives for the contract period (must be related to the stated mission);

- Constraints envisaged by the SOE and intended strategies to deal with the constraints;

- Performance targets for the contract period, including assumptions made as well as strategies to achieve the targets set;

- Commitments made by both parties ( SOE and government) during the contract period;

- Available incentives/sanctions for performance during the contract period;

- The responsibilities of SEC in monitoring and evaluating the SOE performance; and

- Other legal considerations in case of dispute.

The officials unanimously noted that the PC process commences with a pre-negotiation meeting followed by an actual negotiation organized by SEC. The next stage is the signing of PC and implementation by the SOE; followed by submission of reports for monitoring and performance evaluation.

\subsubsection{Pre-Negotiation Meeting and Actual Negotiation}

There is no specific date on which this meeting comes off, but all the interviewees noted that the meeting often takes place in the month of October preceeding the contract period. This meeting aims at discussing actual negotiation format, obligations of government, dividend policy and payment of dividend, payment of taxes and debt servicing, responsibilities of SOE board members, payment of staff bonuses, weight for performance indicators, and the need to organize Annual General Meeting (others call it Stakeholders' Meeting) to present audited financial reports and appoint or endorse their external auditor (field interviews). Before the actual day of negotiation, SEC formally writes to each SOE usually in November requesting for three key documents for study: SOE budget for the year, corporate plan (often three to five years), and a draft performance contract. Officials of SEC specifically noted that SEC assists some of the SOEs in the preparation of their corporate plans and draft PCs when such documents are found to be substandard. These documents according to the officials provide the basis for assessing the quality of performance targets and corporate plans of SOEs. Compared to the responses received from officials at the sector ministries and MOF, the focus of government representatives is different in that they appear to be only interested in some specific targets (e.g. dividend payment) quality of performance targets), thus play little role to ensuring that targets set are not "soft".

Separate negotiations are held between SEC and each SOE, the parent ministry and MOF on three areas: the past performance with respect to targets in the PC in operation; their expectations in the budget which must be consistent with the content of corporate plans; and the draft performance contract prepared based on the SOE's corporate plan and budgets. The discussions commence with presentations made by each SOE which focus on the economic and political environments; operational results (efficiency and productivity); and financials (past and expectations). Furthermore, targets set by the SOE and performance evaluation 
criteria weights proposed in consultation with the sector ministries (especially in the area of projects and policies) are presented and discussed. These presentations set the stage for intense discussions which sometimes span over three (3) hours.

Officials (SOEs) observe that representatives from government almost always appear unprepared to probe the presentations rendering the exercise a two-way discussion (between SOE and SEC only). They unanimously argue that the active participation of government representative would contribute significantly to the process. SEC confirmed this and added that as mangers of PC, they seek for innovative ways, i.e. trend analysis of figures in their past audited annual reports, and monitoring reports on their operations and assumptions (exchange rates, inflation and interest rates) to raise queries where appropriate. They therefore believe equal commitment from the other representatives of government will ensure quality goals and desirable outcome from the implementation of PCs. Similarly, some SOEs do not attach importance to the process. Officials for SEC explain that the SOEs that take the PC process seriously have over the years experienced significant improvement in various areas of their operations.

The forgoing observations suggest the lack of commitment from some government representatives which can also affect the commitment of SOEs. Commitment is a critical element to ensuring desirable outcome (Fryer, et al, 2009; Heslin, et al, 2008; Locke \& Latham, 1990, 2002, 2006). Further, this confirms the argument that commitment on the part of SOE leadership is vital if well-defined objectives are formulated, and that will ultimately affect quality of performance targets set (Fryer, et al, 2009).

In the specific case of the quality of targets negotiated and agreed, many scholars argue that targets set by SOEs are easy. Though these concerns may be genuine, evidence so far provided is anecdotal and appears to be only based on performance targets (see Shirley \& Xu, 1998). Empirical evidence of scores obtained by SOEs in Ghana over some years shows otherwise. The performance scores are based on performance targets in four broad areas: Financial/Economic; Efficiency/Productivity; Dynamic Effects ${ }^{3}$ and; Management Improvement/ Projects.

As can be seen from table 2, the number of SOEs that score below $80^{4}$ has been increasing. In 1990 , about $27 \%$ of the SOE failed to reach the pass mark, increased to $44 \%$ and reduced to $31 \%$ of SOEs. In $1996,50 \%$ of the SOEs failed to achieve a pass mark. Data on subsequent years is likely to confirm that targets set are not easy as postulated by existing literature on PCs (Shirley \& Xu, 1998, 2001; Weitzman, 1980). It is also an indication of SEC's effectiveness in negotiating for quality targets.

\footnotetext{
3 This element was proposed in 1998 and implemented in 1999.

4 This is the mark that earns a recommendation for reward (see details in next sub-section on performance evaluation).
} 
Table 2: Frequency distribution of SOE Performance Index scores for some Years

\begin{tabular}{lcccc}
\hline Score & 1990 & 1994 & 1995 & 1996 \\
\hline $60-69.99$ & $0 \%$ & $8 \%$ & $9 \%$ & $18 \%$ \\
$70-79.99$ & $27 \%$ & $36 \%$ & $22 \%$ & $32 \%$ \\
$80-89.99$ & $67 \%$ & $48 \%$ & $53 \%$ & $32 \%$ \\
$90-100$ & $1 \%$ & $8 \%$ & $16 \%$ & $18 \%$ \\
\hline Total & 100 & 100 & 100 & 100 \\
\hline Ave. score & 82 & 79 & 82 & 79 \\
\hline
\end{tabular}

Source: Authors compilation from SOE performance Evaluation Reports during the early years

\subsubsection{Contract Signing and Execution}

On account of the foregoing presentations and discussions, the draft PCs are revised and finalized. SEC then organizes a ceremony where parties to the contract sign, in order to make the document ready for implementation. The contract is signed by the CEO/MD, MOF, the sector ministry, and SEC as the referee.

The execution stage from the data collected determines the success or otherwise of the PC system. Officials of one SOE (from the excellent category) explain that once the content of the PC is agreed, the targets are discussed with all functional heads who contributed to the formulation and setting of objectives and performance targets. With approval from the board of directors, the targets are integrated into the overall performance management system of the organization. This is done by decentralizing and linking the targets to all functional departments and individual staff performance measurement and evaluation. They added that the internal auditor department is furnished with the agreed performance targets and assigned the task of monitoring and reporting on performance. This is not the case in the other SOEs as in this article. They only discuss the targets with unit heads, but there are no arrangements to encourage committed contributions from employees. In other words, there seem to be no relationship between PC targets and performance management system of the SOE in the lower category (average and fair), but aligning these related performance systems is critical to experience improved performance in public sector organizations (Fryer, et al., 2009).

Furthermore, the decentralization of the targets setting process and implementation encourages commitment from leadership and staff, hence their relatively good performance (Fryer, et al, 2009; Heslin, et al, 2008; Locke \& Latham, 1990, 2002, 2006).

\subsubsection{Performance Monitoring and Reporting}

It is the responsibility of SEC to monitor SOEs performance and report accordingly. SEC does this by relying on quarterly reports submitted by SOEs. These reports are used to assess 
target presented during negotiation (past reports), monitoring, and evaluating performance of the enterprises against the various targets set out in the performance contracts. Sometimes, SEC undertakes on-site visits to monitor physical projects, and discuss challenges being encountered by the SOEs. Feedbacks are provided after these exercises for the necessary action to be taken.

Analysis of some quarterly reports show that the information provided usually covers the financial and operational areas, including capital projects and cash flow. Specifically, the reports include progress made by the Managing Director on behalf of the SOE, achievements with respect to negotiated performance targets, deviation from agreed targets and explanations, comparison of actual and budgeted operating performance, etc.

On account of the above, SEC reports to the stakeholders outlined in PNDCL 170. The report highlights the performance of SOEs against the negotiated targets; any key deviations from plans and budgets, the causes of such deviations, identified external factors including government policies that has affected or has the potential of affecting SOE performance, the overall performance of the management and staff of SOEs, and recommendations for rewards and sanctions where applicable. Top on the list is the Office of the Vice President of the Republic of Ghana. Copies are made available to the parent ministries, MOF, Office of the Speaker of Parliament (the legislature), any other SOE supervisory and regulatory body, and the SOEs themselves.

These arrangements are consistent with recommendations from the literature on goal setting theory and performance management, but what is not clear is the extent to which the foregoing stakeholders in SOE sector use the feedbacks to ensure improved SOE performance (Fryer, et al, 2009; Heslin, et al, 2008).

\subsubsection{Performance Evaluation and Rewards/Sanction}

This stage of the PC process is undertaken after the contract period; usually the second quarter of the next contract period. This is so because the evaluation takes into account all quarterly reports (all four quarters) from SOEs, monitoring reports, reviews, and audited annual report. Based on the negotiated and agreed performance targets set for the year, SEC reviews actual performance and scores each SOE along three indicators created from the four major areas of performance targets mentioned earlier. Each major area is assigned a weight to reflect its importance in the overall performance measurement ${ }^{5}$. Historically the weights assigned to each area are Financial/ economic (50\%); Efficiency/productivity (35\%); and Management improvements/ projects (15\%). Since 1999, the performance indicators and weights have changed to Financial/ economic $(50 \%)^{6}$; Dynamic effect $(30 \%)$ and Management improvements/ projects (20\%).

The aggregate of the weighted scores produces what is known as performance evaluation score or the Performance Index Score for the SOEs. Under this evaluation system, a score of 60 is the lowest possible score and 100 is the highest score. However, only scores above 80 qualify for a recommendation of reward (performance evaluation); and scores below 70

\footnotetext{
5 The sum of all weights must equal 100 .

${ }^{6}$ Efficiency/productivity is used for sub-vented SOEs.
} 
qualify for a sanction recommendation.

In addition, qualitative reviews of the performance trend of each SOE, including the factors that contributed to/ or hindered improved performance are taken into account during the performance evaluation. These confirm the evidence that the standard for evaluating SOEs under the PC system is high.

\section{Concluding Remarks}

This article mainly examines the PC system as a performance management tool drawing on the Goal setting theory. This appears to be the first time that the adopted theory has applied to the PC system of SOEs and perhaps as a performance management tool in the public sector of a developing country.

Evidence gathered show that the PC system has multiple aims, but ultimately ensures improved SOE performance. In practice, the PC system follows standardized processes; pre-negotiation, actual negotiation, signing and execution, monitoring and reporting, and performance evaluation for reward or sanction. In addition, the format of each PC is the same regardless of the nature and sector that the SOE operates. However, there are some variations in the financial targets influenced by the objective of the SOE under consideration.

During the PC process, parties to the contract participate fully in the process, but there seem to be little or no commitment from some SOEs (especially those in the average and fair category) and government (representative), especially in the areas of corporate planning, setting and negotiation of targets, and execution of PCs. These affect SOE performance. Though performance targets of SOEs in Ghana are not easy compared to international standards, active participation and commitment from government representatives other than SEC to the process can ensure improved SOE accountability and performance, as well as reduce the formulation of "soft" goal and targets.

From the foregoing, the study shows that some fundamental elements of goal-setting theory are generally consistent with the PC system practiced by SOEs in Ghana, and perhaps other countries. For instance, findings confirm some links between the formulation of vision, mission, goals, objectives (corporate planning) and performance of individuals and organizations (SOEs). Therefore, corporate planning remains a key element of any PC in order to ensure the desired outcomes.

However from the evidence, there are varying degree of commitment across the cases in the study. Indeed, the SOEs committed to the process (excellent and above average categories), integrate the entire PC process into their existing performance management system and decentralized to employee levels, and they perform relatively well. In other words, there is the need to link the PC system with performance management at employee level.

On the basis of the above, this paper recommends the need to create an environment and structures that encourage commitment from the leadership and staff of SOEs as well as representatives from government to achieve negotiated and agreed targets. This may be achieved effectively through the issue of enforceable guidance to standardize the internal arrangements made by SOEs for achieving the processes in the PC system. Furthermore, 


\section{Macrothink}

Journal of Public Administration and Governance ISSN 2161-7104 2013, Vol. 3, No. 2

SOEs and government must move away from the perception that the PC system is just an annual routine exercise. Future studies may therefore explore the principles of goal setting theory on a large scale by comparing the PC systems operated by SOEs and traditional civil service. Furthermore, the performance targets and objectives may be evaluated in line with perspectives proposed in balanced scorecard, performance prisms, etc.; explore the relationship between PC system and conventional performance management systems; and ascertain the extent to which each system can contribute to organizational performance.

\section{References}

Appiah-Kubi, K. (2001). State-owned enterprises and privatisation in Ghana. The Journal of Modern African Studies, 39(2), 197-229.

Ayee, J. R. (2008). The balance sheet of decentralization in Ghana. In Foundations for Local Governance (pp. 233-258). Physica-Verlag HD.

Bandura, A. (1997). Self-efficacy: The exercise of control. Worth Publishers.

Bass, B M. (1985). Leadership and performance beyond expectation, New York: Free Press.

Baum, J. R., \& Lock, E.A. (2004). The Relationship of Entrepreneurial Traits, Skill and Motivation to Subsequent Venture. Journal of Applied Psychology, 89(4), 587-598.

Binderkrantz, A.S., Holm, M., \& Korsager, K. (2011). Performance Contracts and Goal Attainment in Government Agencies. International Public Management Journal, 14(4), 445-463.

Baum, R., Locke, E., \& Smith, K. (2001). A multi-dimensional model of venture growth. .Academy of Management Journal, 44, 292-303.

Caulfied, J.L.(2006). The Politics of Bureau Reform in Sub-Saharan Africa. Public Administration and Development, 26(1), 15-26.

Cavalluzzo, K.S., \& Ittner, C.D. (2004). Implementing Performance Measurement Innovations: Evidence from Government. Accounting, Organizations and Society, 29(3): 243-267.

Christensen, P.F. (1998), Performance and Divestment of State-Owned Enterprises in Ghana. Public Administration and Development, 18(3), 281-293.

Chun, Y.H., \& Rainey, H. G. (2005a). Goal Ambiguity in US Federal Agencies. Journal of Public Administration Research and Theory, 15(1), 1-30.

Chun, Y.H., \& Rainey, (2005b). Goal Ambiguity and Organisational Performance in US Federal Agencies. Journal of Public Administration Research and Theory, 15(4), 529-557.

Divestiture Implementation Committee [DIC] (1999), DIC, June. Divestiture of State-Owned Enterprises in Ghana, Accra.

Dlamini, M.P. (2001). Contract Plans and Public Enterprise Performance the Case of Swaziland. CAFRAD (African Training and Research Centre in Administration for Development). 


\section{Ml Macrothink}

Journal of Public Administration and Governance ISSN 2161-7104 2013, Vol. 3, No. 2

Fryer, K., Anthony, J. \& Ogden, S. (2009). Performance Management in the Public Sector. International Journal of Public Sector Management, 22(6), 478- 498.

Glesne, C., \& Peshkin, P. (1992). Becoming qualitative researches: An introduction. Longman:New York.

Heslin, P.A., Carson, J. B., \& VandeWalle, D. (2008). Practical Applications of Goal- Setting Theory to Performance Management. In J.W. Smiter, (Eds), Performance Management: Putting Research into Practice (pp. 89-116). San Francisco, CA: Jossey Bass.

Hood, C. (1991). A Public Administration for All Seasons. Public Administration, 69(1), 3-19.

Hood, C. (1995). The "New Public Management in the 1990s: Variations on a Theme. Accounting Organisations and Society, 20(2), 93-109.

Hyndman, N., \& Eden, R. (2001). Rational Management, Performance Targets and Executive Agencies: Views from Agency Chief Executives in Northern Ireland. Public Administration, 79(3), 579-598.

Islam, N. (1993). Public Enterprise Reform: Managerial Autonomy, Accountability and Performance Contracts. Public Administration and Development, 13(2), 129-152.

Ittner, C.D., \& Larker, D.F. (2001). Assessing Empirical Research in Managerial Accounting: A Value-Based Management Perspective. Journal of Accounting and Economics, 32(1), $349-410$.

Johnsen, Å. (2012). Why Does Poor Performance Get So Much Attention in Public Policy? Financial Accountability \& Management, 28(2), 121-142.

Jones, L. (1991). Performance Evaluation from Public Enterprises. Discussion Paper 22. World Bank.

Kaplan, R.S. (2001). Strategic Performance Measurement and Management in Non-Profit Organizations. .Non-Profit Management and Leadership, 11(3), 353-70.

Killick, T. (1978). Development Economics in Action: a study of economic policies in Ghana. London: Heinemann.

Larbi, G. (2001). Performance Contracting in Practice: Experience and Lessons from the Water Sector in Ghana, Public Management Review, 3(3), 305-324.

Latham, G.P., Borgogni, L., \& Petitta, L. (2008). Goal setting and performance management in the public sector. International public management Journal, 11(4), 385-403.

Latham, G. P., \& Locke, E. A. (2007). New developments in and directions for goal-setting research. European Psychologist, 12(4), 290-300.

Locke, E. A., \& Latham, G. P. (2006). New directions in goal-setting theory. Current Directions in Psychological Science, 15(5), 265-268.

Locke, E.A., \& Latham, G.P. (1990). A Theory of Goal Setting and Task Performance. Prentice-Hal: New Jersey, Englewood-Cliffs. 


\section{Al Macrothink}

Journal of Public Administration and Governance ISSN 2161-7104 2013, Vol. 3, No. 2

Locke, E.A., \& Latham, G.P. (2002). Building a Practically Useful Theory of Goal Setting and Task Motivation. American Psychologist, 57(9), 705-17.

Mallon, R.D. (1994). State-owned Enterprise Reform through Performance Contracts: The Bolivian Experiment. World Development, 22(6), 925-934.

Nellis, J., \& Kikeris, S. (1989). Public Enterprise Reform: Privatization and the World Bank. World Development, 17(5): 659- 672.

Nellis, J. (1989). Contract Plans and Public Enterprise Performance. World Bank Discussion. Paper No. 48, World Bank, Washington, DC.

Omoyefa, P.S. (2008). Public Sector Reforms in Africa: A philosophical Re- Thinking. Africa Development, 33(4), 15- 30.

Opoku, G.B.K. (1997). Planning, monitoring and evaluation system performance Contracting: the Ghanaian experience. Paper presented at International Conference on Performance Contracting, January 13-15, New Delhi.

Organization for Economic Co-operation and Development [OECD], (1999). Performance Contracting: Lessons from Performance Contracting Case Studies, Framework for Public Sector Performance Contracting, Paris.

Osborne, D., \& Gaebler, T. (1992). Reinventing Government: How the Entrepreneurial Spirit is Transpforming the Public Sector. Addison Wesley, Reading MA.

Rangan, V.K. (2004). Lofty Missions, Down-to-earth Plans. Harvard Business Review, 82(3), $112-119$.

Schacter, M. (2000). Public Sector Reform in Developing Countries; Issues, Lessons and Future Directions. Prepared For Policy Branch, Canadian International Development Agency.

Schick, A. (1998). A Contemporary Approach to Public Expenditure Management Washington: World Bank Institute.

Shirley, M. (1998). Trends in Privatization. Economic Reform Today, 1, 8-10.

Shirley, M. (1989). Evaluating the Performance of Public Enterprises in Pakistan. Policy Planning Research Working Paper, 160, World Bank, Washington, D.C.

Shirley, M., \& Xu, L.C. (2001). Empirical effects of performance contracts: Evidence from China. Journal of Law, Economics and Organizations, 17(1), 168-200.

Shirley, M. M., \& Xu, L. C. (1998). Information, incentives, and commitment: an empirical analysis of contracts between government and state enterprises. Journal of Law, Economics, and Organization, 14(2), 358-378.

Simpson, S.N.Y., \& Onumah, J.M. (2010). Performance Contracts and State Enterprises: The Ghanaian Perspective. African Journal of Administrative Studies, 75, 19-35.

State Enterprises Commission (SEC). (1995). SOE Programme: Review and Recommendations 1984 - 1994 for 1995- 2000, Accra. 


\section{Macrothink}

Journal of Public Administration and Governance ISSN 2161-7104 2013, Vol. 3, No. 2

State Enterprises Commission (SEC). (1992). Review of Legal and Institutional Framework of SOEs, Accra, Ghana.

State Enterprises Commission (SEC), Law 1987, PNDC Law, 170.

Trivedi, P. (1990). Lack of Understanding in Memorandum of Understanding. Economic and Political Weekly, November 24.

Trivedi, P. (2005). Designing and Implementing Mechanisms to Enhance Accountability for State-owned Enterprises. Expert Group meeting on Reinventing Public Enterprise and Management, October 27-28. United Nations Department of Economic and Social Affairs (UNDESA) Division of Public Administration and Development Management.

Uddin, S., \& Hopper, T. (2003). Accounting for privatization in Bangladesh: testing World Bank claims. Critical Perspectives on Accounting, 14(7), 739-74.

United Nations Report (1995). Performance Contracting for Public Enterprises. United Nations, New York, U.S. Library of Congress.

Verbeeten, F.H.M. (2008). Performance Management Practices in Public Sector Organizations Impact on Performance. Accounting, Auditing and Accountability Journal, 21(3), 427-454.

Weitzman, M. L. (1980). The Ratchet Principle and Performance Incentives. The Bell Journal of Economics, 11(1), 302-308.

White, S., \& Locke, E. (2000). Problems with the Pygmalion effect and some proposed solutions. The Leadership Quarterly, 11(3), 389-415.

World Bank (1995). Bureaucrats in Business: The Economics and Politics of Government. World Bank Policy Research Report. Washington DC.

World Bank (1983). World Development Report. Washington, DC. 